\title{
Advanced Manufacturing for Nuclear Core Design
}

\section{Approved for public release.} Distribution is unlimited.
B. R. Betzler

B. J. Ade

A. J. Wysocki

M. S. Greenwood

J. J. W. Heineman

P. C. Chesser

P. K. Jain

F. Heidet, ANL

A. Bergeron, ANL

August 16, 2019 


\title{
DOCUMENT AVAILABILITY
}

Reports produced after January 1, 1996, are generally available free via US Department of Energy (DOE) SciTech Connect.

Website www.osti.gov

Reports produced before January 1, 1996, may be purchased by members of the public from the following source:

\author{
National Technical Information Service \\ 5285 Port Royal Road \\ Springfield, VA 22161 \\ Telephone 703-605-6000 (1-800-553-6847) \\ TDD 703-487-4639 \\ Fax 703-605-6900 \\ E-mail info@ntis.gov \\ Website http://classic.ntis.gov/
}

Reports are available to DOE employees, DOE contractors, Energy Technology Data Exchange representatives, and International Nuclear Information System representatives from the following source:

Office of Scientific and Technical Information

PO Box 62

Oak Ridge, TN 37831

Telephone 865-576-8401

Fax 865-576-5728

E-mail reports@osti.gov

Website http://www.osti.gov/contact.html

This report was prepared as an account of work sponsored by an agency of the United States Government. Neither the United States Government nor any agency thereof, nor any of their employees, makes any warranty, express or implied, or assumes any legal liability or responsibility for the accuracy, completeness, or usefulness of any information, apparatus, product, or process disclosed, or represents that its use would not infringe privately owned rights. Reference herein to any specific commercial product, process, or service by trade name, trademark, manufacturer, or otherwise, does not necessarily constitute or imply its endorsement, recommendation, or favoring by the United States Government or any agency thereof. The views and opinions of authors expressed herein do not necessarily state or reflect those of the United States Government or any agency thereof. 


\section{ADVANCED MANUFACTURING FOR NUCLEAR CORE DESIGN}

B. R. Betzler

B. J. Ade

A. J. Wysocki

M. S. Greenwood

J. J. W. Heineman

P. C. Chesser

P. K. Jain

F. Heidet, Argonne National Laboratory

A. Bergeron, Argonne National Laboratory

August 2019

Prepared by

OAK RIDGE NATIONAL LABORATORY

Oak Ridge, TN 37831-6283

managed by

UT-BATTELLE, LLC

for the

US DEPARTMENT OF ENERGY

under contract DE-AC05-00OR22725 



\section{CONTENTS}

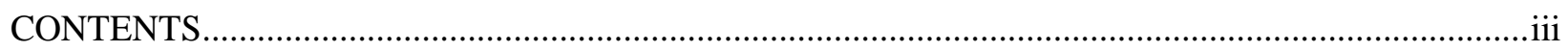

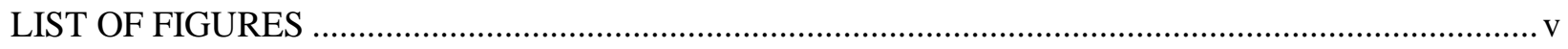

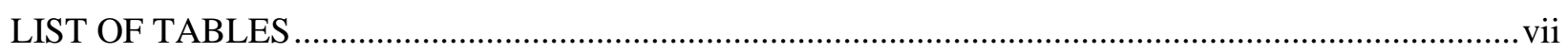

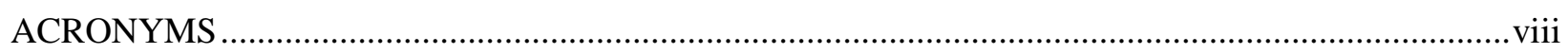



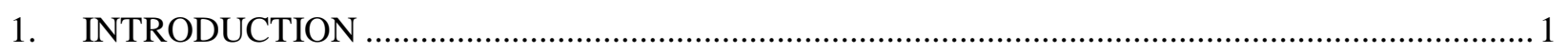

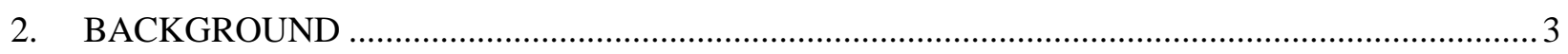



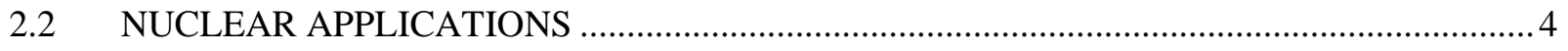

3. CORE DESIGN WITH ADDITIVE MANUFACTURING ........................................................... 7

3.1 DESIGN ENVELOPE AND REQUIREMENTS …............................................................ 7





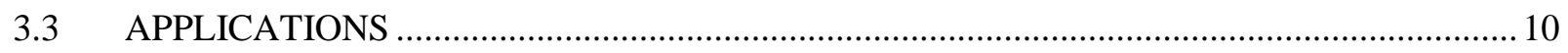

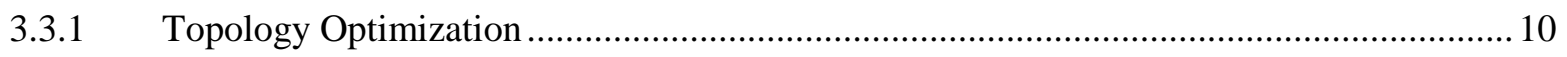



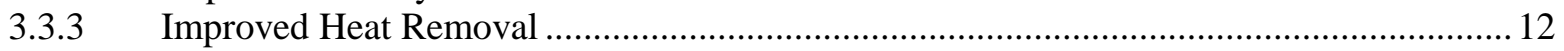

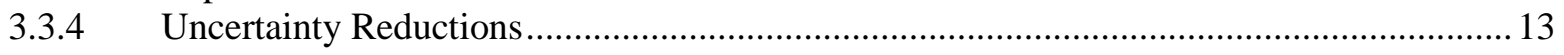

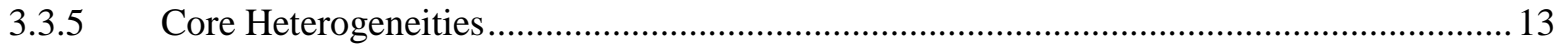

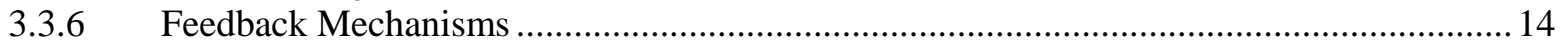

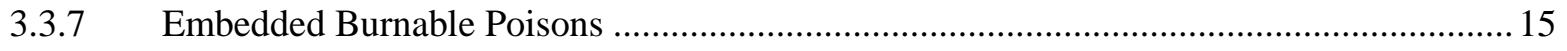

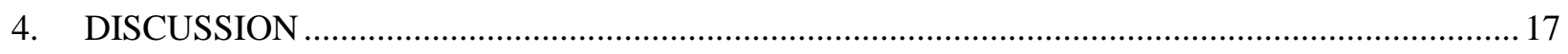

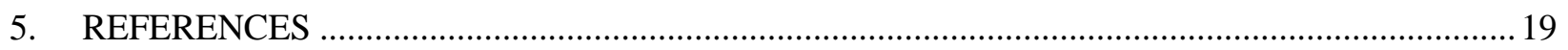




\section{LIST OF FIGURES}

Figure 1. Pressure vessel head manufactured with powder metallurgy and hot isostatic pressing

[6].

Figure 2. Control elements for HFIR manufactured with ultrasonic additive manufacturing [9]

Figure 3. Ceramic-metallic surrogate fuel elements manufactured using hot isostatic press and pulsed electric current techniques [10].

Figure 4. Inputs to the reactor licensing process leading to source term quantification [29].

Figure 5. Sample of structures minimalized to maintain performance and reduce material volume.......... 11

Figure 6. Candidate spring-like structures to enhance heat transfer between the cladding wall (shown) and fuel form (not shown).

Figure 7. An example of design flexibility for coolant flow optimization.

Figure 8. An example visualization of material data generated from in situ monitoring of an additively manufactured component.

Figure 9. Example core radial dependencies on coolant flow area. The coolant flow area is larger near the center of the core where more power is produced relative to the periphery.

Figure 10. Example metallic structures intended to change geometry based on temperature. With a temperature increase, this tab bends away from the cladding, pushing against adjacent structures

Figure 11. Example tomogram of embedded particle distributions within complex sample geometries that may be leveraged for integrating burnable poisons. 


\section{LIST OF TABLES}

Table 1. Power densities, fuel geometries, and active core height for selected reactor designs................. 8 


\section{ACRONYMS}

AGR advanced gas-cooled reactor

ANL

Argonne National Laboratory

ATR

Advanced Test Reactor

BWR

boiling water reactor

CASL

Consortium for Advanced Simulation of Light Water Reactors

DOE

US Department of Energy

HFIR

High Flux Isotope Reactor

IRT

LWR

Research Reactor Thermal

MITR

MTR

light water reactor

MURR

NBSR

Massachusetts Institute of Technology Reactor

Materials Test Reactor

NEAC

PWR

Missouri University Research Reactor

National Bureau of Standards Reactor

Nuclear Energy Advisory Committee

TCR

pressurized water reactor

TRIGA

Transformational Challenge Reactor

VVR

Training, Research, Isotopes, General Atomics

Water-Water Reactor 


\begin{abstract}
Advanced manufacturing technologies are fundamentally altering the way components are designed and manufactured. The potential application space for these technologies within the nuclear industry is broad, with the most benefit realized from the ability to approach the nuclear core design problem from an advanced manufacturing perspective. One of the objectives of the US Department of Energy Office of Nuclear Energy (DOE-NE) Transformational Challenge Reactor (TCR) design and analysis activities is to demonstrate this approach.

A mitigation of conventional constraints realized through advanced manufacturing methods opens up the design space, enabling a departure from typical axially uniform pin- and plate-type geometries common to operating nuclear reactors worldwide. The ability to use more heterogenous spatial and material flexibilities increases the demand on the predictability of higher fidelity modeling and simulation tools to be used in the design, analysis, and optimization processes. Leading candidate advanced manufacturing technologies for nuclear applications are additive methods that provide for high dimensional control and incorporation of small design features such as powder bed fusion, laser directed energy deposition, and binder jetting.

Potential applications to core design identified during DOE-NE TCR design and analysis activities fall into two categories: those that are uniquely enabled by additive manufacturing technologies and those that are enabled by the characteristics (e.g., repeatability and instrumentation) inherent to these technologies. Identified applications include reducing in-core parasitic materials, improving heat conduction across fuel-cladding gaps, optimizing thermal hydraulic design with flexible coolant flow geometries, reducing uncertainties in manufactured components, optimizing core conditions with design heterogeneities, designing feedback mechanisms using material characteristics, and embedding burnable poisons. These potential applications join a host of nuclear industry advanced manufacturing activities to recapture manufacturing capabilities, reduce manufacturing costs and complexities, reduce deployment time, and enable performance and operational enhancements.
\end{abstract}




\section{INTRODUCTION}

Continued developments in advanced manufacturing technologies are fundamentally altering the way components are designed and manufactured. The potential application space for these technologies within the nuclear industry is very broad due to the rigorous requirements and inherent multidisciplinary nature (e.g., civil, mechanical, electrical, and nuclear engineering) of large nuclear power plants. Beyond applications for existing nuclear reactors, these new manufacturing methods, advanced materials, and dimensional constraints can be applied to the nuclear core design problem. ${ }^{a}$ This manufacturing-informed design approach has the potential to yield the most benefit from the application of advanced manufacturing in the nuclear industry-leveraging advanced materials, data science, and rapid testing and deployment to drive down costs and development times, ultimately improving future commercial viability. This approach is being demonstrated under the US Department of Energy Office of Nuclear Energy (DOE-NE) Transformational Challenge Reactor (TCR) effort.

Nuclear reactor design includes nuclear, thermal hydraulic, fluid mechanics, and thermomechanical components. An understanding of complex dynamic behaviors and feedback mechanisms is necessary to quantify conditions during steady-state operation and during potential transient scenarios to ensure fission product retention and safe reactor operation. These complex physics behaviors and rigorous requirements drive reactor design and modeling and simulation methods development: the simulation of this complex physics problem is simplified for more repeating core geometries. With additional consideration of fabrication (e.g., materials, densities, dimensions), fuel cycle (e.g., fuel shuffling and cycle lengths), and performance (e.g., power density and peak temperatures) complexities, axially uniform plate- or pin-type fuel geometries are ubiquitous. Most research and commercial reactors use repeating fuel geometries. With recent advances in modeling and simulation, fuel vendors have developed more heterogeneous, higher performance fuel geometries that are still based on these repeating geometries.

When the constraints of conventional manufacturing methods are relaxed, the design space opens enabling exploration of more heterogeneous geometries with spatial geometry and material flexibility. Additional modeling and simulation advancements must be implemented to quantify the design performance of these more complex geometries and predict conditions during steady-state and transient scenarios to the rigor required for a reactor safety basis, including associated uncertainties and safety margins. The degree of benefit that can be realized from this design flexibility depends on the desired performance metrics (e.g., peak temperature and fuel utilization) and design envelope (e.g., core size and power density limits). More benefits may be realized given a small core size constraint relative to an unbounded size constraint. For example, there may be fewer benefits from advanced manufacturing approaches for large light water reactor (LWR) fuel assemblies.

This report discusses applications of advanced manufacturing technologies to the core design problem as informed by the design and analysis activities of the DOE-NE TCR. Current advanced manufacturing methods and identified advanced manufacturing applications in nuclear are discussed briefly. This is not intended as a complete discussion of potential applications or quantification of the benefits from this manufacturing-informed approach, but it is a discussion of the potential benefits for desired reactor metrics.

\footnotetext{
a In this context, the core design space is defined openly in the approach to determining an acceptable configuration of fuel, cladding, moderator, coolant, and other materials. In the commercial nuclear reactor industry, core design refers to the determination of a fuel assembly loading pattern at the beginning of each cycle.
} 


\section{BACKGROUND}

Advanced manufacturing technologies comprise a constantly evolving set of methods that reimagine the approach to traditional manufacturing processes, tapping into multiple advances across many fieldscomputer modeling, advanced instrumentation, data science, and automation - to recapture manufacturing capabilities, improve component performance, and reduce component costs and development and procurement lead times. Current activities in the nuclear industry are targeting some of these objectives.

\subsection{ADVANCED MANUFACTURING}

Advanced manufacturing is a broad technical term for the use of innovative technologies to improve processes or products. Due to its revolutionary potential and increased private and public investment, industries such as aerospace, transportation, construction, manufacturing, and nuclear are pursuing advanced manufacturing applications. Examples of successful applications include:

1. redesign of manufacturing components (e.g., composite molds) with additive and subtractive techniques to reduce lead times for delivering these components, enabling a more rapid designbuild-test cycle [1,2],

2. redesign of existing multi-part transportation components (e.g., aerospace) for additive manufacturing processes to reduce part count and weight [3], and

3. development of manufacturing methods for existing components using additive and subtractive techniques to reduce scrap metal waste [4].

These examples encompass some of the most direct benefits of advanced manufacturing processes: redesigning components or fabrication processes to maintain or improve performance and reduce material use, weight, lead times, or wastes. In many cases, the requirements in these redesigning processes are defined to ensure consistent or better mechanical performance relative to a traditionally manufactured part, to improve performance, and to reduce material use and waste when possible.

Leading candidate advanced manufacturing technologies for nuclear reactor core applications include powder bed fusion, laser directed energy deposition, and binder jetting with additional densification techniques [5]. These additive technologies are summarized here; a more complete discussion is provided in "Considerations for Application of Additive Manufacturing to Nuclear Reactor Core Components" [5].

1. Powder bed fusion builds components layer by layer by melting thin layers of powder.

2. Laser directed energy deposition builds components by generating a small melt pool into which additional metal powder is blown.

3. Binder jetting uses a solvent-polymer solution to bind powder and build a low-density part. Follow-on sintering or other densification techniques are commonly used.

Along with their own unique challenges, these technologies adhere to general additive manufacturing principles:

1. For additive manufacturing technologies, an increase in the material deposition rate generally results in poorer dimensional control. Geometries with smaller (e.g., millimeter-scale) features generally require technologies with high dimensional control, limited manufacturing envelopes (e.g., $80 \times 40 \times 50 \mathrm{~cm}^{3}$ ), and lower depositions rates. 
2. Minimum comfortable geometric feature sizes for additive technologies are on the 100-mircon scale.

3. Designs requiring smoother surfaces than provided during the additive process must accommodate post-machining techniques.

4. Additive manufacturing of a given material is unique. For example, a process or method for a given steel alloy may not be applicable for a different steel alloy.

5. Hybrid systems deploying both additive and subtractive methods or using two different materials are still being actively researched and developed.

6. Several trial builds are needed to refine the build parameters and approach to successfully manufacture a given component.

7. Due to the rapid development in advanced manufacturing technologies, new literature must be reviewed no less than every four years [5].

\subsection{NUCLEAR APPLICATIONS}

Nuclear industry investments in advanced manufacturing technologies have focused on several nuclear components to recapture manufacturing capabilities, reduce manufacturing costs and complexities, and enable performance or operational enhancements.

1. The only available vendors for large LWR pressure vessels are international, which is a national strategic disadvantage. Efforts are under way to develop pressure vessels using hot isostatic pressing (Figure 1) to recapture some of this capability domestically for small modular reactors [6]. Other efforts focused on wire additive direct energy depositions have yielded large metal structures $[7,8]$ that are directly relevant to large nuclear reactor structural components (e.g., reactor pressure vessel and piping).

2. High Flux Isotope Reactor (HFIR) control elements are large, thin cylindrical plates that are conventionally manufactured through powder metallurgy and explosive forming. Thin tolerances (e.g., small cladding thickness) and rigorous requirements for these components have driven activities in ultrasonic additive manufacturing (Figure 2) with the objective of reducing cost for making conforming reactor components [9].

3. Efficient nuclear thermal propulsion requires very high coolant outlet temperatures, resulting in high material temperatures, temperature gradients, and fine geometries. For some of the advanced materials able to withstand these conditions, no traditional manufacturing methodology exists (Figure 3). Therefore, advanced manufacturing methods are being explored [10].

These activities are only a sampling of the active work in advanced manufacturing in the nuclear industry. 


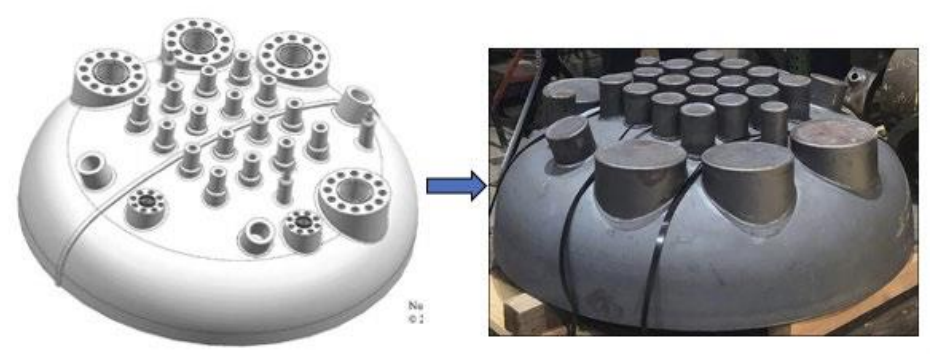

Figure 1. Pressure vessel head manufactured with powder metallurgy and hot isostatic pressing [6].
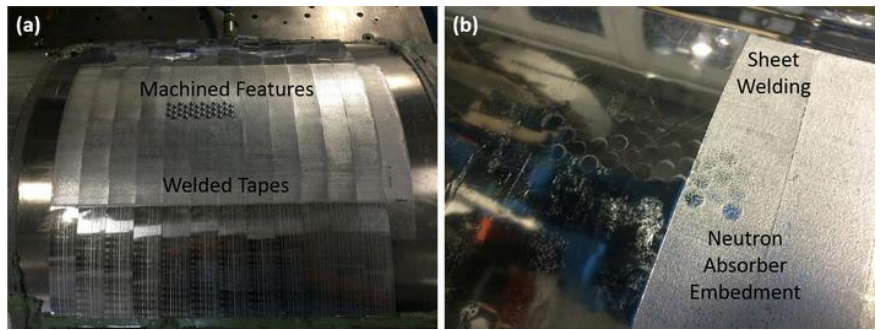

Figure 2. Control elements for HFIR manufactured with ultrasonic additive manufacturing [9].

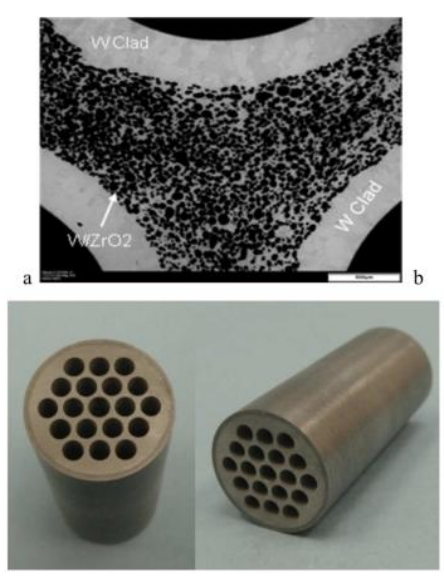

Figure 3. Ceramic-metallic surrogate fuel elements manufactured using hot isostatic press and pulsed electric current techniques [10].

The following additional potential activities for advanced manufacturing in the nuclear industry were identified through other TCR activities in the Technologies to Reactors workshop [11], through the instrumentation and control thrust area [12], and the nuclear fuels development thrust area [13].

1. Developing manufacturing surveillance processes to provide additional data that may be used to help understand material properties, predict performance, and meet specifications [11].

2. Deploying additive manufacturing processes to provide for the rapid manufacturing and deployment of replacement parts [11].

3. Redesigning existing and new components using advanced manufacturing to improve performance or reduce cost [11]. 
4. Deploying additive manufacturing technologies to provide for rapid prototyping to shorten development times for new designs and materials [11].

5. Reimagining nuclear core design to leverage advanced manufacturing processes to optimize nuclear performance [11].

6. Embedding sensors inside of components to provide additional data during operation to monitor core hot spots or component performance over the lifetime of a part $[11,12]$.

7. Developing heterogeneous fuel monolithic structures to improve cost and performance (e.g., fuel utilization) [13].

8. Developing advanced matrices for particle and dispersion fuels free from conventional processes to accurately control distributions, increase matrix quality and packing fractions, and reduce design uncertainties [13].

Ongoing applications of advanced manufacturing within the nuclear industry fit into one or more of these identified areas of interest. The discussion herein pertains to item 5, leveraging additive manufacturing technologies to reimagine nuclear core design and optimize nuclear performance. 


\section{CORE DESIGN WITH ADDITIVE MANUFACTURING}

A nuclear core is a configuration of materials designed to safely generate neutrons and/or thermal energy using a controlled fission reaction. Most operating cores consist of pin- or plate-type fuel geometries arranged in a repeating lattice. This design is used in part due to three major drivers:

1. Plates, tubes, and cylindrical fuel rods are relatively simple to manufacture, particularly when the same fuel pin or plate is repeated throughout the geometry. ${ }^{\mathrm{b}}$

2. Repeating geometries are expandable (i.e., configurable to different sizes), and if necessary, they may be broken down further to implement cost-effective maintenance and fuel management approaches such as assembly loading patterns, fuel shuffling, and operating cycle times.

3. Simple, axially uniform repeatable geometries are easier to simulate than more complex heterogeneous geometries. ${ }^{c}$ The predictability of modeling and simulation tools is necessary to ensure that the system will remain in a safe condition during steady-state and transient scenarios.

In addition to these operating core designs, many reactor core concepts have been developed. However, many of these are impractical with respect to material limitations, economic concerns, or safety issues. Some of these core designs do not consider manufacturability. In core design informed by additive manufacturing, most restrictions from current conventional processes are alleviated, but the expandability and simulatability of repeatable geometries still impacts the design process. The benefits of these relaxed constraints are discussed along with the design process below.

\subsection{DESIGN ENVELOPE AND REQUIREMENTS}

Nuclear cores are heat-generating systems that must be carefully designed to sufficiently extract thermal energy while retaining fission products. ${ }^{\mathrm{d}}$ The design purpose often defines the solution:

1. Most large commercial reactors (Table 1) have repeating pin-type geometries broken into subassemblies for fuel cycle management. Long, thin tubes are relatively easy to manufacture and seal, and they are mechanically robust.

2. Pin- and plate-type fuel geometries are common in research reactors worldwide (Table 1). Many of these systems have a relatively low power density [14].

3. Cores in high-performance research reactors in the United States (Table 1) consist of thin fuel plates. These cores have relatively short fuel elements, and most have very high power densities. The geometry of thin plates is more effective than the geometry of a thin cylinder for high fuelto-cladding ratios and effective cooling.

Any limitation on core size has a significant impact on the resulting design.

\footnotetext{
$\mathrm{b}$ This is as perceived from current conventional processes.

c The first nuclear reactors were designed without computers.

${ }^{d}$ This discussion pertains to cores with solid fuels in which the integrity of the fission product boundary (i.e., cladding) is paramount.
} 
Table 1. Power densities, fuel geometries, and active core height for selected reactor designs.

\begin{tabular}{lccc}
\hline Fuel type & $\begin{array}{c}\text { Typical core power } \\
\text { density [kW/L-core] }\end{array}$ & $\begin{array}{c}\text { Active core } \\
\text { height [m] }\end{array}$ & $\begin{array}{c}\text { Fuel geometry } \\
\text { type }\end{array}$ \\
\hline Commercial reactor fuels & & & \\
\hline PWR & 100 & 3.66 & pin \\
BWR & 50 & $3.05-3.66$ & pin \\
AGR [15] & 3 & 8.30 & pin \\
\hline Research reactor fuels & & & \\
\hline MTR [16] & varies & 0.61 & plate \\
TRIGA [17] & varies & 0.36 & pin \\
VVR [18] & varies & 0.60 & plate \\
IRT [19] & varies & 0.60 & plate \\
\hline High-performance research reactor fuels & & \\
\hline ATR [20] & 1,000 & 1.18 & plate \\
MITR [21] & 70 & 0.57 & plate \\
HFIR [22] & 1,700 & 0.51 & plate \\
NBSR [23] & 40 & 0.56 & plate \\
MURR [24] & 300 & 0.61 & plate \\
\hline
\end{tabular}

For core design activities, the objective is to determine an acceptable configuration of fuel, cladding, coolant, moderator (if applicable), and other materials. An acceptable core design satisfies the targeted performance metrics; is coolable, safe, and controllable under all anticipated conditions; and uses compatible materials $^{\mathrm{e}}$ that behave well in a high radiation environment. The relative importance of the different performance metrics, such as overall cost, fuel utilization, and cycle length, is dependent on the deployment objectives, and shapes the optimized design [25].

Despite these constraints, the design space remains flexible, with a given design dependent on the end use. Additive-manufacturing-informed core design enables more complex geometries and heterogeneities that may be leveraged to improve performance or operational margins over designs constrained by conventional processes. Even for existing nuclear plants, changes in fuel assembly design have been made over the years to improve fuel cycle economy and reduce fuel failures:

1. Boiling water reactor (BWR) fuel assemblies have evolved over the years to adopt smaller fuel rods, more complex gadolinia rod loading patterns [26], axial variations, and more complex water box geometries [27].

2. Pressurized water reactor (PWR) assemblies have evolved to adopt tighter fuel rod lattices, axial heterogeneities, and burnable absorbers [28].

These additional assembly design complexities are enabled by improved modeling and simulation capabilities that accurately predict the performance of these geometries. These design updates, modeling and simulation advancements, and operational knowledge have contributed to power uprates and license extensions for existing nuclear power plants.

${ }^{\mathrm{e}}$ Common materials used in nuclear reactors include ceramic and dispersion fuels; corrosion-resistant zirconium and aluminum cladding; graphite, beryllium, heavy water, and light water moderators; and gaseous and water coolants. The majority of operating reactors worldwide are water-cooled and/or -moderated reactors. 


\subsection{MODELING AND SIMULATION}

Traditional core modeling and simulation uses simplified models and methods due to their computational efficiency. The core geometries developed using the new flexibility proffered by additive manufacturing may not be amenable to these simplified modeling and simulation procedures or tools. High-fidelity modeling and simulation tools developed in recent years may be required to quantify performance enhancements, and validation is critical for providing confidence in these predictions. Meanwhile, a nuclear reactor will always be held to the same safe operation requirements to mitigate radiological releases (Figure 4). Thus, modeling and simulation plays a significant role in defining optimized geometries for core design.

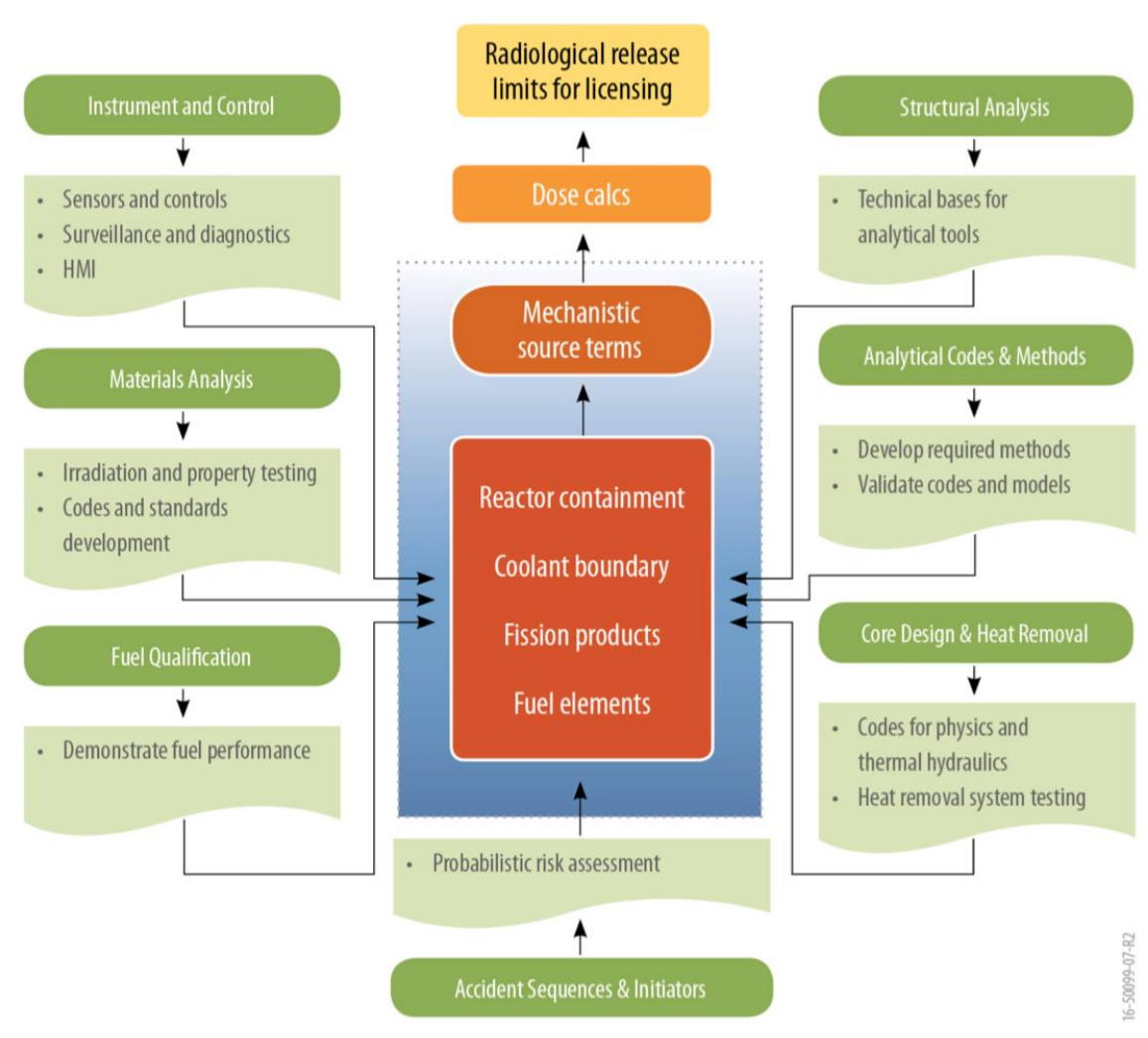

Figure 4. Inputs to the reactor licensing process leading to source term quantification [29].

\subsubsection{Tools}

The major modeling and simulation components for core design include reactor physics (radiation transport and depletion), thermal hydraulics, system dynamics, and thermomechanical analysis including fuel performance. During steady-state operation, the core design problem is a coupled reactor physicsthermal hydraulics problem: fission and radiation heat generated within the fuel material is transferred through the matrix or across the gap and/or cladding, into the coolant, and out of the core. Thermomechanical tools predict material behavior and stresses at these temperatures. System dynamics tools are required to predict behavior and quantify conditions during some transient scenarios to determine peak temperatures and heating rates. Reactor physics methods predict core characteristics as conditions change over the cycle (e.g., fuel depletion) and associated outcomes. The physical and chemical change in fuel material during depletion and its impact on the cladding is a fuel performance problem. 
Years of development has yielded the methods and procedures currently deployed for operating reactors that sufficiently predict conditions during steady-state and transient scenarios [30]. Many of these methods leverage the simplified geometries with one-dimensional (1D) or two-dimensional (2D) models, leverage axial uniformity for thermal hydraulic models, adopt simplified methods such as point kinetics for dynamic modeling, and apply uncertainty factors and safety margins are to ensure conservative predictions. In some cases, tools are more safety-specific — as when calculating margin to fuel failurethan predictive. The simplicity of these tools is useful for meeting software quality assurance requirements.

The current industry standard for reactor physics simulations of large BWR and PWR cores is the twostep method [31]. This method leverages the relatively long height of the core and the axial geometric uniformity to model fuel assemblies using 2D geometry. The characteristics, or coarse group constants, of these 2D simulations are stored and passed to full-core simulations that model the core as separate sets of assemblies or nodes. These full-core simulations predict burnup, determine fuel loading patterns, and back out reconstructed pin powers. These computationally efficient methods are optimized for these designs.

The Consortium for Advanced Simulation of LWRs (CASL) targeted more advanced methods to enhance the operational performance, efficiency, and safety of LWRs [32]. The main CASL product is the Virtual Environment for Reactor Applications (VERA), which simulates the operation of an entire PWR down to the characteristics of a single fuel rod, including coupling reactor physics, thermal hydraulics, and fuel performance tools [33]. Instead of using the two-step method for reactor physics, this tool uses a 2D/1D method that leverages the fact that the majority of the assembly heterogeneities are in the radial dimension, and axial heterogeneities may be captured using a simpler 1D solution. These tools are still newly developed and have yet to be adopted by industry for use in core design.

The most high-fidelity methods for core design include high-fidelity Monte Carlo transport and computational fluid dynamics (CFD). These methods are more intractable for core design applications due to computational expense, but they have recently been applied in operating reactors [34]. In addition, providing validation data for CFD simulations is absolutely necessary to verify the method for the application. For thermomechanical analysis, a host of finite-element based tools are available. For nuclear fuel applications, the MOOSE-based BISON tool, developed by the DOE-NE Nuclear Energy Advanced Modeling and Simulation [35,36] and maintained by Idaho National Laboratory, is an ideal tool.

\subsection{APPLICATIONS}

Several potential applications of additive manufacturing technologies have been identified and are being explored as part of the TCR design and analysis activities. Some applications are more advanced than others; this serves as a brief summary of these discussions. Fuel design [13] and embedded instrumentation [12] applications are not included in this discussion, but they are being explored.

\subsubsection{Topology Optimization}

Structural and cladding materials within a nuclear core support fuel and retain fission products. Parasitic neutron absorption in these materials contributes negatively to the fuel cycle economy of the reactor, so reducing the amount of these materials within the core without adding risk to component critical functions has a positive effect on performance and cost savings.

Additive manufacturing processes are currently used in several industries to build minimalized geometries of existing components to reduce weight or waste. In nuclear design, the requirements are more complex, as the material must withstand a high radiation environment and changing temperature gradients for the lifetime of the given component. These complex designs (Figure 5) must perform well 
thermomechanically. Performance enhancements from a neutron economy perspective are relatively simple to quantify using geometric or material density changes; the benefits depend on the material composition and the amount removed. Potential applications in BWRs and PWRs include channel box, grid spacers, bottom nozzles, and upper fuel handling mechanisms.


Figure 5. Sample of structures minimalized to maintain performance and reduce material volume.

\subsubsection{Gap Conductivity}

In BWRs and PWRs, an engineered fuel-cladding gap is designed into the fuel rods to accommodate the dimensional changes of the fuel pellet during irradiation at operating temperatures and to reduce the impact of the resulting pellet-cladding interaction on fuel integrity. This gap causes poor heat transfer between the fuel and the cladding, resulting in a large temperature drop (on the order of $100{ }^{\circ} \mathrm{C}$ in PWR) across this gap and an elevated peak fuel temperature. Improving conductivity across this gap would reduce the temperature drop.

Additive manufacturing processes can be used to manufacture cladding down to a few hundred microns in dimension, with very thin internal spring-like structures to accommodate a fuel form and to improve heat transfer across the gap between the form and the cladding wall. These spring-like structures (Figure 6) may be optimized to accommodate the dimensional changes within the fuel during reactor operation and to ensure contact with the fuel form at all times, which is important to ensure consistent heat transfer. While simulation tools are reasonably predictive, with additive-enabled rapid prototyping and testing, several geometries may be built to measure the heat transfer characteristics and validate models. One potential drawback of this feature is that it adds material to the system that may increase parasitic neutron capture. 

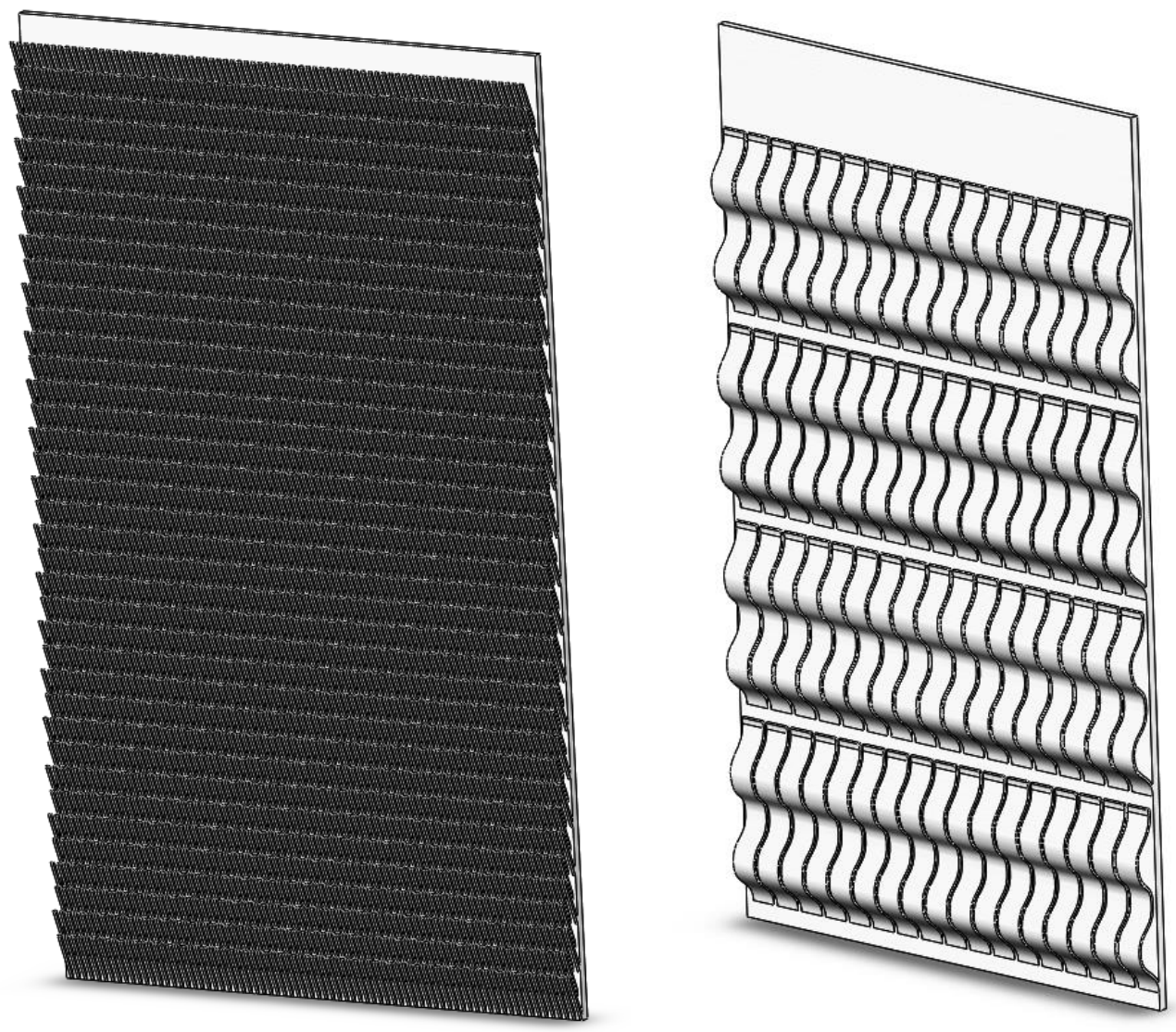

Figure 6. Candidate spring-like structures to enhance heat transfer between the cladding wall (shown) and fuel form (not shown).

\subsubsection{Improved Heat Removal}

The heat transfer between a fissioning fuel form and a forced flowing coolant depends on several factors, including geometries, materials, fluid type, flow rates, and power density. Optimizing this heat transfer requires balancing performance metrics such as peak temperatures, and constraints such as pressure drop and pumping power, and it requires system design information.

Additive manufacturing-informed heat exchanger designs are currently in development. Similar principles in design and analysis may be adopted for core design, as the fuel material in the core may be seen as the hot side of a heat exchanger. Additive manufacturing processes may facilitate departure from the typical axially uniform geometries, defining coolant flow paths that vary in the axial dimension to improve heat transfer into the flowing coolant (Figure 7). For these new designs, the roughness of additively manufactured components may be leveraged to improve turbulent heat transfer. Flow geometries may be designed to enhance bulk coolant mixing, particularly in the lateral direction, to reduce peak temperatures. Diverging from axial uniformity significantly increases computational burdens, increasing the importance of high-fidelity simulations to validate cases and provide confidence in results. The thermal-hydraulic performance of these designs has implications for safety during transient scenarios; these physics must be factored into these analyses. 




Figure 7. An example of design flexibility for coolant flow optimization.

\subsubsection{Uncertainty Reductions}

Factors are applied in safety calculations to account for material correlation uncertainties, material property uncertainties, and potential deviations of as-built parts within the specified design tolerance [37]. These uncertainty factors are applied to ensure conservative estimates of peak temperatures and safety margins.

Greater dimensional control in additive manufacturing processes may enable a reduction in these uncertainty factors. These uncertainties are derived from the design tolerances, which depend on manufacturing processes. In situ monitoring during additive manufacturing processes such as high speed video and infrared thermography (Figure 8) captures specific deviations from the as-designed component. Greater dimensional control and in situ monitoring may enable reductions in uncertainty to allow for operation closer to design limits, potentially improving reactor performance.

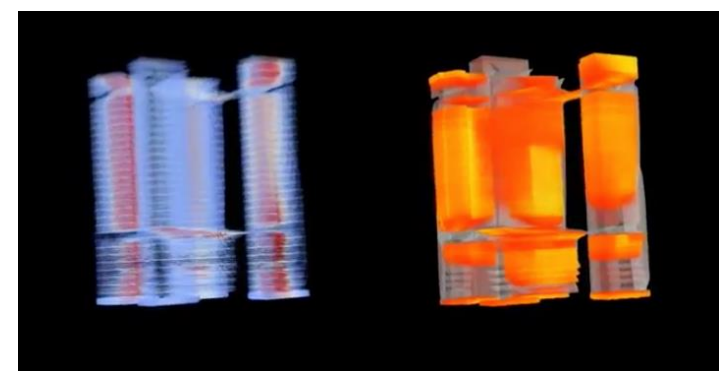

Figure 8. An example visualization of material data generated from in situ monitoring of an additively manufactured component.

\subsubsection{Core Heterogeneities}

The theoretical core power distribution for an approximately cylindrical and homogeneous core mimics a cosine function in the axial dimension and a Bessel function in the radial-azimuthal dimensions [30]. The ideal core power shape is more well behaved and uniform than this, and it may be achieved through a designed variation in fuel distributions or fuel-to-moderator ratios.

The dimensional control and automation in additive manufacturing processes may make heterogeneous core geometries more economically feasible. For example, each fuel rod in a Westinghouse $17 \times 17$ lattice is essentially identical to the others, which simplifies the conventional manufacturing and fueling processes. Additive processes are more amenable to the manufacturing of heterogeneous geometries. This may be leveraged to optimize power distribution within the core. In addition, the flow paths of coolant 
running through the core may be tailored to match this core power distribution, directing more coolant to the hotter regions of the core (Figure 9). Smooth transitions are achievable with additive processes that would allow for a flatter distribution in a characteristic of interest such as power. These core heterogeneities increase the burden on reactor physics and thermal hydraulic simulations of the system, but some core symmetry would likely still apply.

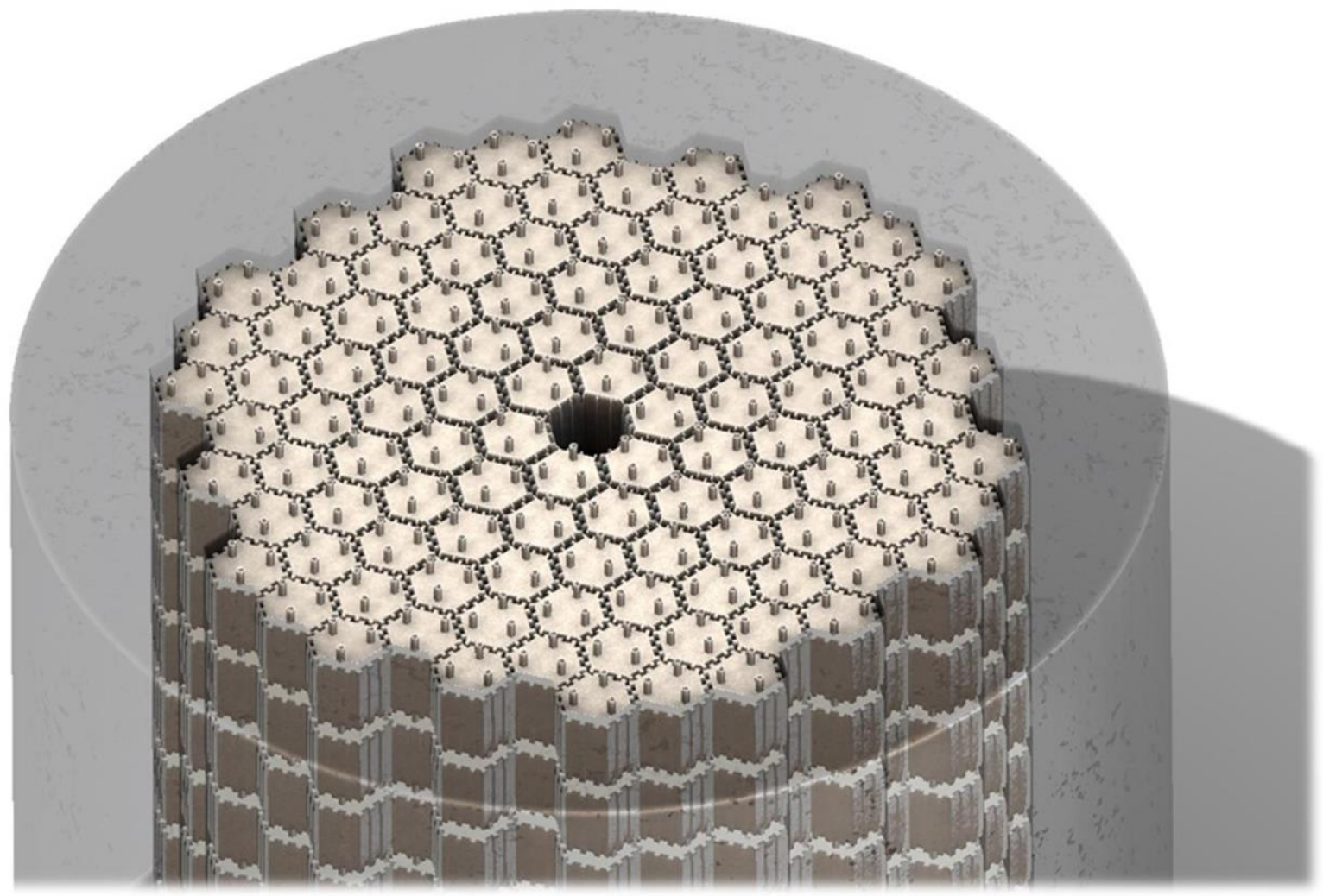

Figure 9. Example core radial dependencies on coolant flow area. The coolant flow area is larger near the center of the core where more power is produced relative to the periphery.

\subsubsection{Feedback Mechanisms}

Most nuclear reactors have feedback mechanisms that provide negative reactivity in the event of a temperature increase. With additional active control mechanisms such as control rods, a negative temperature reactivity coefficient ensures the safe operation of a reactor, avoiding a runaway reaction scenario that could lead to fuel failure. In some cases, the physics of a reactor can make it difficult to design a core with a negative temperature reactivity coefficient. For some of these systems, such as the Fast Flux Test Facility, active or passive reactivity feedback devices are designed to provide for this additional negative feedback in even the most challenging accident scenarios [38].

Additive manufacturing processes can be used to incorporate features to provide for a specific behavior in temperature. A spring-like or tab-like structure additively manufactured with one or more materials (Figure 10) may be designed to provide a specific dimensional response to increased temperature. This behavior could be designed to change coolant flow areas in response to temperature changes or to provide negative reactivity feedback in the event of a transient. Geometric feedbacks must be tested, validated, and implemented into reactor physics and thermomechanical tools to quantify their effects. 


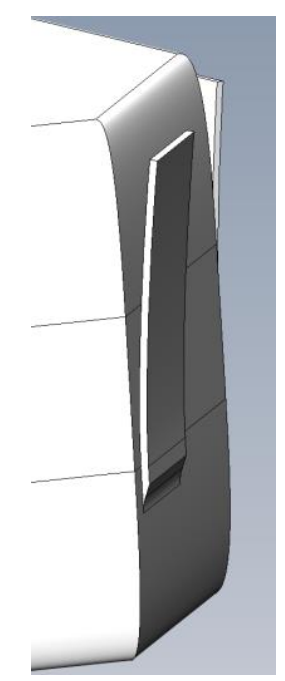

Figure 10. Example metallic structures intended to change geometry based on temperature. With a temperature increase, this tab bends away from the cladding, pushing against adjacent structures.

\subsubsection{Embedded Burnable Poisons}

Burnable poisons may be incorporated into core designs to limit excess reactivity to enable long-term reactivity control, providing for a long fuel cycle. Burnable poisons also control power distributions over the lifetime of the core. Both BWRs and PWRs use some form of burnable poisons, including gadoliniadoped rods, insertable absorber rods, and/or absorber coatings on fuel pellets. These burnable absorbers are useful for counteracting initial excess reactivity and to provide a longer cycle length without the need for refueling.

The dimensional control of additive manufacturing processes provides for more flexibility in burnable absorber concentration and distribution (Figure 11). In addition, a burnable absorber may be embedded or distributed within the matrix or in other materials during the additive processes.

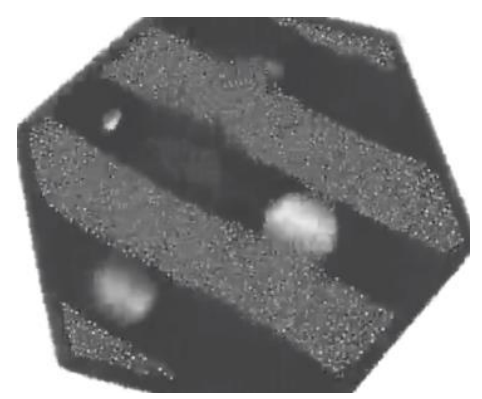

Figure 11. Example tomogram of embedded particle distributions within complex sample geometries that may be leveraged for integrating burnable poisons. 



\section{DISCUSSION}

Several potential improvements and impacts in core design that may be realized through additive manufacturing are discussed in Section 3.3:

1. topology optimization

2. gap conductivity

3. improved heat removal

4. uncertainty reductions

5. core heterogeneities

6. feedback mechanisms

7. embedded burnable poisons

This is only a partial list of some discussions from the TCR design and analysis activities. Advanced modeling and simulation are critical for quantifying the performance enhancements for some of these design improvements.

Some of these potential improvements are uniquely enabled by additive manufacturing technologies (e.g., material reduction), while some represent the application of additive manufacturing to make heterogeneous designs more feasible (e.g., fuel loading distribution). This distinction is important: in some cases, increasing design complexity does not require additive manufacturing; however, additive manufacturing may ultimately enable this design complexity through process automation, in situ monitoring, and repeatably. In addition, certain design complexities are implemented more easily though additive manufacturing processes. Implementing a core design that leverages many of these design improvements is the focus of the TCR design and analysis thrust. 


\section{REFERENCES}

[1] Guinness World Records Limited. Guinness World Records 2016 "Largest solid 3D-printed item," Guinness World Records, 29 August 2016, Accessed July 29, 2019, https://www.guinnessworldrecords.com/world-records/432579-largest-solid-3d-printed-object.

[2] Post, B. K., P. C. Chesser, R. F. Lind, A. Roschli, L. J. Love, K. T. Gaul, M. Sallas, F. Blue and S. Wu. 2019. "Using Big Area Additive Manufacturing to directly manufacture a boat hull mould," Virtual and Physical Prototyping 14:2, 123-129, DOI: 10.1080/17452759.2018.1532798

[3] DeHoff, R. R., C. Tallman, C. E. Duty, W. H. Peter, Y. Yamamoto, W. Chen, and C. A. Blue. 2013. "Case Study: Additive Manufacturing of Aerospace Brackets," Advanced Materials and Processes 171:3, 19-22.

[4] Holshouser, C., C. Newell, S. Palas, C. E. Duty, L. Love, V. Kunc, R. Lind, P. Lloyd, J. Rowe, R. Dehoff, W. Peter, and C. Blue. 2013. Out of Bounds Additive Manufacturing," Advanced Materials and Processes 171:3, 15-17.

[5] Simpson, J., J. Haley, C. Cramer, O. Shafer, A. Elliott, W. Peter, L. Love, and R. DeHoff. 2019. Considerations for Application of Additive Manufacturing to Nuclear Reactor Core Components, ORNL/TM-2019/1190, Oak Ridge National Laboratory (ORNL).

[6] Gandy, D., and G. Stover. 2018. "Advanced Manufacturing to Enable the Next Generation of Nuclear Plants," Presentation at Molten Salt Reactor Workshop - Creating a Self-Sustaining Environment for MSR Success, October 3-4, 2018.

[7] Greer, C., A. Nycz, M. Noakes, B. Richardson, B. Post, T. Kurfess, and L. Love. 2019. "Introduction to the design rules for Metal Big Area Additive Manufacturing," Additive Manufacturing 27, 159-166. https://doi.org/10.1016/j.addma.2019.02.016.

[8] Sridharan, N., M. W. Noakes, A. Nycz, L. J. Love, R. R. Dehoff, and S. S. Babu. 2018. "On the toughness scatter in low alloy C-Mn steel samples fabricated using wire arc additive manufacturing," Materials Science and Engineering: A 713, 18-27. https://doi.org/10.1016/j.msea.2017.11.101.

[9] Hehr , A., J. Wenning, K. A. Terrani, S. S. Babu, and M. Norfolk. 2016. "Five-axis ultrasonic additive manufacturing for nuclear component manufacture," JOM 69:3, 485-490.

doi:10.1007/s11837-016-2205-6.

[10] Houts, M. G., S. K. Borowski, J. A. George, T. Kim, W. J. Emrich, R. R. Hickman, J. W. Broadway, H. P. Gerrish, and R. B. Adams. 2012. "Nuclear Thermal Propulsion for Advanced Space Exploration," Proceedings of Space Propulsion 2012, Bordeaux, France, May 7-10, 2012.

[11] Tobin, K., and S. Aumeier. 2018. Technologies to Reactors: Enabling Deployment of Nuclear Energy Systems, ORNL-SPR-2018/1025, Oak Ridge National Laboratory (ORNL).

[12] Cetiner, S. M. and P. Ramuhalli. 2019. Transformational Challenge Reactor Autonomous Control System Framework and Key Enabling Technologies. ORNL/SPR-2019/1178, Oak Ridge National Laboratory (ORNL). doi:10.2172/1530084.

[13] Nelson, A. T. 2019. Features that Further Performance Limits of Nuclear Fuel Fabrication: Opportunities for Additive Manufacturing of Nuclear Fuels. ORNL/SPR-2019/1183, Oak Ridge National Laboratory (ORNL).

[14] NEAC. 2017. Nuclear Energy Advisory Committee. Assessment of Missions and Requirements for a New US Test Reactor. Accessed August 5, 2019.

[15] Nonbøl, E. 1996. Description of the Advanced Gas Cooled Type of Reactor (AGR). Ris $\varnothing$ National Laboratory Report, NKS/RAK2(96)TR-C2. 
[16] Miller, R. F. and R. L. Sindelar. 1995. Analysis for Materials Test Reactor (MTR Fuel Assemblies in Dry Storage). WSRC-TR-95-0121, Westinghouse Savannah River Company.

[17] Cammi, A., M. Zanetti, D. Chiesa, M. Clemenza, S. Pozzi, E. Previtali, M. Sisti, G. Magrotti, M. Prata, and A. Salvini. 2016. "Characterization of the TRIGA Mark II reactor full-power steady state," Nuclear Engineering and Design 300, 308-321. https://doi.org/10.1016/j.nucengdes.2016.01.026.

[18] Pond, R. B., N. A. Hanan, J. E. Matos, and C. Maraczy, 1998. "A Neutronic Feasibility Study for LEU Conversion of the Budapest Research Reactor," Proceedings of the International Meeting on Reduced Enrichment for Research and Test Reactors, Sao Paulo, Brazil, October 18-23, 1998.

[19] Hanan, N. A., U. S. Salikhbaev, S. Baytelesov, and A. A. Dosimbaev. 2006. "WWR-SM Conversion to LEU IRT-4M Oxide Fuel," Proceedings of the International RERTR Meeting, Cape Town, South Africa, October 29-November 2, 2006.

[20] Stanley, C. J., and F. M. Marshall. 2008. "Advanced Test Reactor - A National Scientific User Facility" Proceedings of $16^{\text {th }}$ International Conference on Nuclear Engineering, Orlando, Florida, May 11-15, 2008. https://www.osti.gov/servlets/purl/934543.

[21] MIT. 2019. Massachusetts Institute of Technology Nuclear Reactor Laboratory: Reactor. Accessed 29 July 2019. https://nrl.mit.edu/reactor

[22] Adamson, G. M. Jr., and R. W. Knight. 1968. HFIR Fuel Element Production and Operation, ORNL-TM-2196, Oak Ridge National Laboratory (ORNL).

[23] Stevens, J. G. 2010. Technical Challenges for Conversion of U.S. High-Performance Research Reactors, NAS/RAS Committee on Conversion of Research Reactors, 29 November 2010.

[24] MU Research Reactor. 2019. University of Missouri. Accessed 29 July 2019. https://www.murr.missouri.edu/about/operations/

[25] Betzler, B. R., D. Chandler, D. H. Cook, E. E. Davidson, and G. Ilas. 2019. "Design optimization methods for high-performance research reactor core design," Nuclear Engineering and Design 352, https://doi.org/10.1016/j.nucengdes.2019.110167.

[26] Rearden, B. T., and M. A. Jessee. 2018. "SCALE Code System," ORNL/TM-2005/39, Version 6.2.3, UT-Battelle, LLC, Oak Ridge National Laboratory, Oak Ridge, Tennessee (2018). Available from Radiation Safety Information Computational Center at Oak Ridge National Laboratory as CCC834.

[27] Gustafsson, T. U. Wetterholm, D. Menoher, J. Blaisdell, and B. Andersson. 2013. Reference Fuel Design SVEA-96 Optima3, WCAP-17769-NP, Westinghouse.

[28] Franceschini, F., et al. 2015. 2015. "AP1000 PWR Startup Core Modeling and Simulation with VERA-CS." Proceedings of Advances in Nuclear Fuel Management V (ANFM 2015), Hilton Head Island, South Carolina, USA, March 29 - April 1, 2015.

[29] Petti, D., R. Hill, J. Gehin, H. Gougar, G. Strydom, F. Heidet, J. Kinsey, C. Grandy, A. Qualls, N. Brown, J. Powers, E. Hoffman, and D. Croson. 2016. "Advanced Demonstration and Test Reactor Options Study,” Idaho National Laboratory Technical Report, INL/EXT-16-37867.

[30] Duderstadt, J. J. and L. J. Hamilton. 1976 Nuclear Reactor Analysis. New York: Wiley.

[31] Smith, K. S. 1980. Spatial homogenization methods for light water reactor analysis, MIT (Doctoral Dissertation).

[32] CASL. 2019. Consortium for Advanced Simulation of Light Water Reactors. Accessed 29 July 2019. https://www.casl.gov. 
[33] Kochunas, B. D. Jabaay, S. Stimpson, A. Graham, T. Downar, B. Collins, K. S. Kim, W. Wieselquist, K. Clarno, and J. C. Gehin. 2015. "VERA Core Simulator Methodology for PWR Cycle Depletion," CASL-U-2015-0155-000, Proceedings of ANS M\&C 2015, Nashville, TN, April 19-23, 2015.

[34] Betzler, B. R., D. Chandler, E. E. Davidson (née Sunny) and G. Ilas. 2017 "High-Fidelity Modeling and Simulation for a High Flux Isotope Reactor Low-Enriched Uranium Core Design," Nuclear Science and Engineering 187:1, 81-99, DOI: 10.1080/00295639.2017.1292090

[35] Williamson, R. L., J. D. Hales, S. R. Novascone, M. R. Tonks, D. R. Gaston, C. J. Permann, D. Andrs, R. C. Martineau, 2012. "Multidimensional multiphysics simulation of nuclear fuel behavior," Journal of Nuclear Materials 423:1-3, 149-163. https://doi.org/10.1016/j.jnucmat.2012.01.012.

[36] NEAMS. 2019. Nuclear Energy Advanced Modleing and Simulation Program. Accessed 29 July 2019. https://neams.inl.gov.

[37] Chandler, D., B. Betzler, D. Cook, G. Ilas, and D. Renfro. 2019. "Neutronic and thermalhydraulic feasibility studies for High Flux Isotope Reactor conversion to low-enriched uranium silicide dispersion fuel," Annals of Nuclear Energy 130, 277-292.

https://doi.org/10.1016/j.anucene.2019.02.037.

[38] Wootan, D. W., R. P. Omberg, T. Sofu, and C. Grandy. 2017. "Passive Safety Testing at the Fast Flux Test Facility Relevant to New LMR Designs," IAEA Proceedings of the International Conference on Fast Reactor and Related Fuel Cycles, Yekaterinburg, Russia, June 26-29, 2017. 
